\title{
Waste enhanced with new values to become a new resource
}

\author{
C. Ceppa \\ Department of architectural and industrial design, \\ Turin Polytechnic, Italy
}

\begin{abstract}
The activity of my PhD Research is based on Systems Design. This theory is about the OUTPUT-INPUT concept: the output of an industry process becomes a resource (input) for another process. The main purpose of the research is the individualization of which kinds of activities of the Piedmont Region (the main business is based on the metal and textile industries, agriculture and breeding) could be linked in order to create an integrated autopoietic system where the output, full of potentiality, is used in another process in order to eliminate wastes. The research subjects are production cycles with these final goals: 1-the achievement of sustainable management of processes wastes; 2-the creation of a sustainable open production system like the natural one, where there are no wastes; 3-the proposal of a sustainable development where local companies are linked to each other in order to obtain zero emissions. The research is focalized on the actual uses of process wastes and in particular on the different kinds of wastes, which kinds are presently reused or disposed of, in order to identify and classify the wastes typologies that will be studied. To decide the possible reuse of output such as resources, the quantity and the quality of wastes are carefully examined and subsequently classified on physics-chemical and biological properties and on the possible fields of reuse. An optimum waste use, through available or innovative technologies, will cause profits and advantages to local companies and the regional economy, new jobs and new local production. The results achieved until now are related to the agriculture and breeding sector: in particular there is evidence of the differences and the advantages (regarding the types of output, output reuses, new resources, costs and profits) between the present productive process, which has a linear structure, and the new one which suggests an open sustainable production system.

Keywords: systems design, sustainable waste management, output-input, reuse of wastes, new local flows of materials, open production system.
\end{abstract}




\section{Introduction}

The growing amount of waste generated by productive activities is becoming an increasingly significant problem with serious damage to human health and the environment. Human beings have realized this situation late on and have tried to solve the problem with solutions that have proven to be insufficient. The reason for this is that production processes have always been considered a sequence of actions, independent of each another, aimed at producing commodities. However the commodities are produced with a considerable amount of waste believed to be an unavoidable result of the manufacturing process, along with the final product. In the current production model, the focus is exclusively on the product, though sometimes supported by a targeted research to minimize the potential negative impacts of the waste produced by the process. There needs to be a change in behavior. In a world of growing complexity, like the one we live in today and especially in the future, we need to broaden our attention to the entire production process, i.e. consider it as a whole [1] and not each individual stage separately. This is one of the principles underlying Systems Design: since every process must be seen from a systemic perspective, its final goal is to achieve production with zero emissions. Production must be seen as a support to society and not its ultimate end. Consequently we must seek new ways of producing that also lead to significant results socially, ethically and environmentally and raise the quality of life.

\section{Methodological approach}

The methodological principle adopted in this doctoral research, carried out in the Ecodesign laboratory of the Turin Polytechnic, totally changes the perspective from which to observe how things are working. According to the first principle of Systems Design, the waste (OUTPUT) of one production process is used as a resource (INPUT) for another production process. The waste product is enhanced with new value and becomes a resource. The resources made available from the enhancement process are used to produce new products based on local knowhow. Thus it becomes possible to create new production scenarios. Companies used to consider their waste products totally useless and to be eliminated. The waste incurred only cost and brought no benefit. Now it can be reused for the survival of another company geographically nearby, which can use it as a raw material to be transformed to acquire value. To avoid creating any more residues, waste or squandering, industrial activity must also think about the operating system par excellence: nature. In nature there is no waste because what one species eliminates is what another species feeds on [2]. Even surpluses are metabolized by the system itself. Material circulates continuously and diversity ensures the capacity to salvage. Applying this principle to productive situations, it becomes possible to design open autopoietic self-sustaining production systems. For the first time new flows of material taken from waste, then enhanced and appreciated as resources, are bringing together different industries that join forces to achieve a reciprocal advantage from the output materials of 
their production processes. Naturally this provides a situation with more than just environmental prospects but the formation of a new business model [3]. Currently we are forced to spend huge sums to eliminate or treat waste. By the proposed methodology and the corresponding reevaluation of the rejected material, it becomes possible to skip treatment costs and create a network for selling one's own output. This generates greater profits and benefits to the territory due to the realization of new enterprises, the development and improvement of the already established enterprises and the creation of new jobs. It is a process deliberately applied locally to enhance local potentials and specificities and strengthen the bond with tradition. Another reason it is applied locally is to avoid the high costs of transportation along with the air pollution it creates. By following the Systems Design methodology, the production world, which today is lacking a truly mature environmentally productive culture, would be able to achieve the goal of zero emissions.

\section{Areas of research}

The availability of many new resources compels research to determine new fields of applications pertinent to the examined territory. In the specific case the area being studied is the Piedmont Region, where the major activities are metalworking, textiles, agriculture and livestock [4]. Regarding the study area it was essential to determine which activities could be connected to each other in an open production system designed to completely re-utilize the scraps and waste produced and reach zero emissions production. Along with this identification, an attentive analysis was made of the statistics taken from the MUD [5] (Consolidated Environmental Declaration Form) where companies are required to declare the waste they produce, collect, treat or eliminate, send to be recycled or transport.

Table 1: Quantity of material that is brought to the dump or destined for other treatments.

\begin{tabular}{|c|c|c|}
\hline waste category & dump & other treatments \\
\hline $\begin{array}{l}\text { wastes from agriculture, } \\
\text { horticulture, aquaculture, silviculture, } \\
\text { hunting and fishing, food treatments } \\
\text { and preparations. }\end{array}$ & 5.421 tons & 62.815 tons \\
\hline
\end{tabular}

The result is that, in the areas of farming and livestock raising, large amounts of material (tens of thousands of tons per year) abounding with potential value is brought to the dump or destined to biological or physical-chemical treatments for the purpose of producing compost or mixtures to be eliminated by scattering them on the soil [6] or storing them in permanent warehouses [7]. All of this is further demonstrated by the statistics for the comparison of the different types of 
waste in the current recycling activities they are subjected to. The result is that a huge amount of material, today seen as waste and not as a resource, is used mainly as fuel or scattered on the soil to benefit agriculture or the environment without taking into consideration that if the waste is contaminated it will pollute the ground on which it is scattered. The subject of this study is therefore production cycles associated with farming and livestock raising for the purpose of proposing a sustainable management of the waste products by using the proposed methodology. The aim of this document is to report two case studies that applied the systemic vision of the entire process. It particularly focuses on the differences and advantages (regarding output, reusing output, new available resources, costs and profits) between the current process and the systemic process proposed in relation to cattle breeding and fruit growing.

\subsection{Cattle - current situation}

The analysis of the food-agricultural sector of cattle on the Piedmontse territory concentrates on an intensive breeding process involving 435.000 heads of cattle and analyzes the current phases of the chain, the incoming resources, the quantity and quality of the waste and final products. The expression "intensive breeding", or "factory farming" [8], refers to a form of cattle breeding that uses industrial and scientific techniques to obtain the maximum quantity of product at the lowest costs by using minimum space for each head of cattle. According to the study conducted on the various phases of the process, it appeared that the phases are considered separate from one another and follow a linear course where the waste is seen as something to throw away and not as a resource for other types of production. The problems caused by this approach are clear in all the phases, starting from the first: feeding. The ingredients of animal feed are derived from crops grown with chemical fertilizers and pesticides such as fungicides and antibiotics, which leave traces inside the animal. The feed also commonly has hormones added to it for the purpose of accelerating and increasing the cattle's body growth. Some of these substances remain in the meat thereby lessening the quality of the meat and milk. The quality is further lowered by the stress experienced by the cows during transportation packed in a truck. The trip to the slaughterhouse is long. The animals are also stressed by being bred in stables where the space is exceedingly small and inadequate. It has already been demonstrated that the living conditions of the animals on farm factories are significantly worse than those of cattle raised in the traditional way, i.e. on vast ranchlands where they are free to move around and graze in the open-air. The food and living conditions of the animals are seen exclusively from the perspective of production. For example, to increase milk production, milk cows are forced to calf every 15 months and a cow's gestation period is nearly as long that of human females. It is clear that the current focus of production is centered on the "quantity" factor without any regard for the health or well-being of the livestock or the final consumer: humans. If they had the opportunity to live healthily with a large enough space around them, greater quality would be obtained. In the current situation the waste products are not reutilized and incur elimination costs. In particular water with milk residues (approximately 310.000 
$\mathrm{m}^{3}$ yearly, of which $5 \%$ is milk) is sent to a waste treatment plant and consequently its protein content is not exploited. The same applies to the blood (approximately 3.000.000 tons per year) produced during the slaughtering phase, also containing meat residues now stocked in dumps without being enhanced or exploited. Though rich in elements such as nitrogen, and therefore harmful to the environment, the cow dung (approximately $22 \mathrm{~kg}$ per head per day) is scattered on the land as a fertilizer, which can only bring negative effects. Therefore many problems were found at every step of the process and significant amounts of material are currently dumped or eliminated. This brings about severe economic losses and harms the environment. In conclusion, the final products of the current process are low-quality meat and milk and hides.

\subsection{Cattle - systemic vision application}

The system being proposed here refers to a farm factory consisting of 35.000 head of cattle whose waste products are used in new production processes. By adopting a systemic vision, the outputs of a system are enhanced with new values, thereby becoming resources. This leads to the elimination of waste treatment costs and brings more profit from the sale of the new resources that each production process provides. In fact it has now become clear that we should not expect the land true produce more, but rather obtain more from what the land produces [9]. The goal is to create an open system and design flows of material that allow new companies to form a synergy to reach zero emissions production thanks to a sustainable management of their waste products. Examining the chain in its complexity allows us to find new opportunities that have remained hidden till now. For example cow dung, as well as stable sawdust (37.000 tons per year), are being used to produce biogas from which carbon dioxide, methane gas and sludge are obtained. The sludge is used as natural compost for agriculture and it benefits the soil. As regards the scraps of the slaughterhouse, the blood has protein and nitrogen-rich content that can be used as natural fertilizer for flowers. The meat waste (approximately 1.200 tons per year) can produce worms that can feed quail: a quail hatches 7-14 eggs per month. This provides us with new highquality products, quail and quail eggs, destined to the final consumer, humans. The water with milk residues (approximately $310.000 \mathrm{~m}^{3}$ yearly, of which $5 \%$ is milk), rich in nutritional properties, is not thrown away but used as food for freshwater fish (e.g. tench). It is obvious that with the new system the focus of production is on quality and consequently on human and animal health. In fact, thanks to the more natural and balanced diet, the well-being of the cattle increases along with the quality of all the final products.

The proposed diet relies on products that are completely natural, derived from systemic cultivations in the local area, such as grapes, other fruit, grains, all grown without using chemical pesticides or fertilizers but using natural methods.

In conclusion, by adopting a systemic vision we obtain a valid alternative to the current management of waste. An entire production chains produces a larger number of products, each having a higher quality. It is even more advantageous 


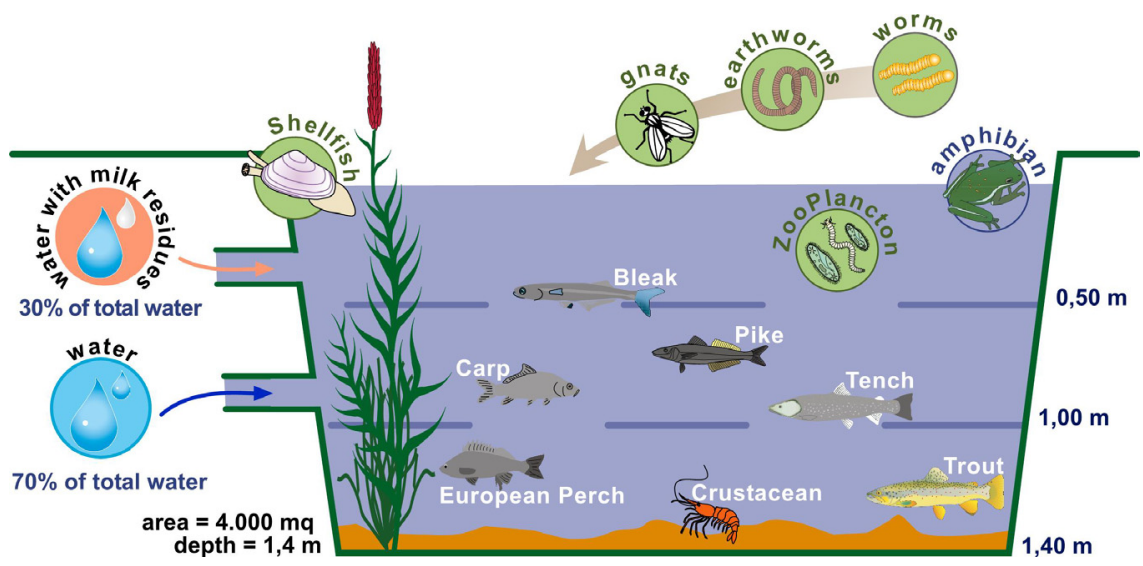

Figure 1: Water with milk residues is used as food for freshwater fish.

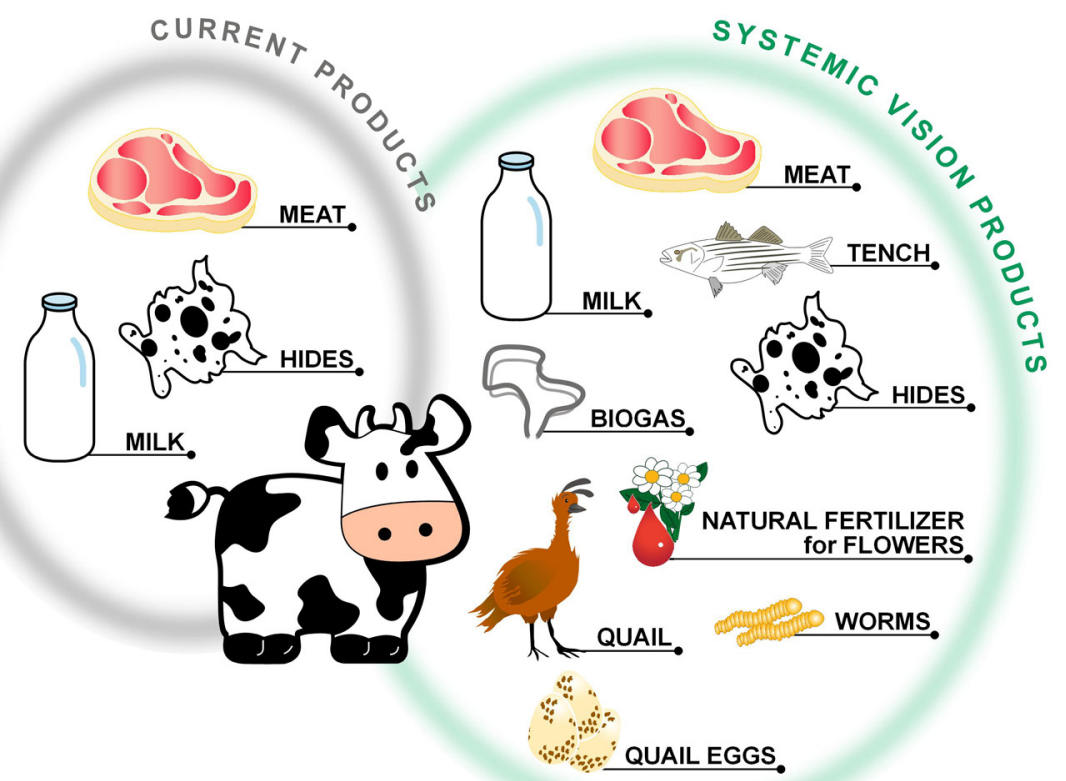

Figure 2: $\quad$ Differences between products from the current cattle breeding and products from the system proposed.

if we consider that on a farm of only 35.000 head (less then $10 \%$ of cattle of the first study: the current situation), if managed systemically, the profit is greater than the current profit from 435.000 head. 


\subsection{Fruit - current situation}

In the second case study we shift our attention to farming, specifically fruit farming. Currently the agri-food sector of fruit in southern Piedmont is characterized by the monoculture of peaches, apples and pears. Peach trees occupy 4.716 ha ( 1 ha $=1.195,9$ square yards), apple trees occupy 3.297 and pear trees occupy 740 hectares. These crops are comparable to each other and therefore can be analyzed together. Some problems are immediately evident during the first phase, i.e. cultivation. This phase makes heavy use of chemical pesticides, such as fungicides, weed killers and insecticides to protect the trees from possible disease and attacks from outside. However, at the same time they harm the quality of the product. Traces of synthetic substances remain on the fruit and undermine the health of the final consumers, humans. There are also problems in the second phase. Pruned material (19 tons per ha) is chopped up and scattered on the terrain as a fertilizer but, since it are contaminated with pesticides previously used on the tree, it considerably pollute the soil. It should be pointed out that the current process also produces special waste [10], which must be eliminated by procedures dictated by the law. These waste products ( $10 \%$ of total fruit production) include all the pieces of fruit discarded in the selection phase because non-conforming to the evaluation criteria, peel scraps and pulp residues from the various processes for producing nectars, juices and purees. Discarding the pulp means the active ingredients contained in it are not exploited. What is truly illogical and paradoxical is that these same active ingredients are created by synthesis and used for cosmetics and pharmaceuticals. It is clear that in this second case study the material to be exploited is stocked at the dump or eliminated, and this has a negative impact on the environment as well as high overhead costs. It is also undeniable that in this process the focus of production is the product, in other words product quantity to the detriment of its quality. We need to change perspective and put humans at the center of the entire issue. We need to be able to offer only quality products for human consumption that have an abundance of social and ethical values.

\subsection{Fruit - systemic vision application}

The availability of new resources urges research that fits the territory analyzed in this paper. Viewing the entire production chain from a systemic perspective, it is possible to completely re-use the waste products that, after being enhanced with new values, become resources. In fact pruning materials (approximately 19 tons per ha) are ground up and completely reutilized. Part is used to create the substrate used for growing mushrooms for human consumption or put in animal feed (e.g. for cattle). Another part becomes sawdust and the remainder is put into a biodigestor to produce biogas. The fruit fallen for the trees $(3 \%$ of total fruit production $=1,9$ tons per ha), till today not gathered and exploited, is used to feed livestock (e.g. cattle). The outputs of the food processing industry are totally reused in other processes. Discarded fruits are also sent to the biodigestor, while the pulp, as well as the peeling and coring scraps, are used for the production of energy and supplement bars $(0,47$ ton per ha) for human consumption, and meal 
for swine and cattle nourishment. Moreover, the output of the fruit peeling and coring process, especially the removal of the skin and seeds, can be used to extract a percentage of pectin $(0,013$ ton per ha), a precious organic compound in foods, pharmaceuticals and cosmetics. By finding interesting fields of application for these new available materials previously considered scraps but now revalued, it was possible to obtain more products, with higher quality, [11] from a grove occupying the same surface area as the current one. All of this was possible thanks to a change in perspective from which to look at the problem. It allowed the production process to obtain higher economic profits, higher quality products enhanced with vital social and ethical values because they take into account human health, animal health and respect for the environment.

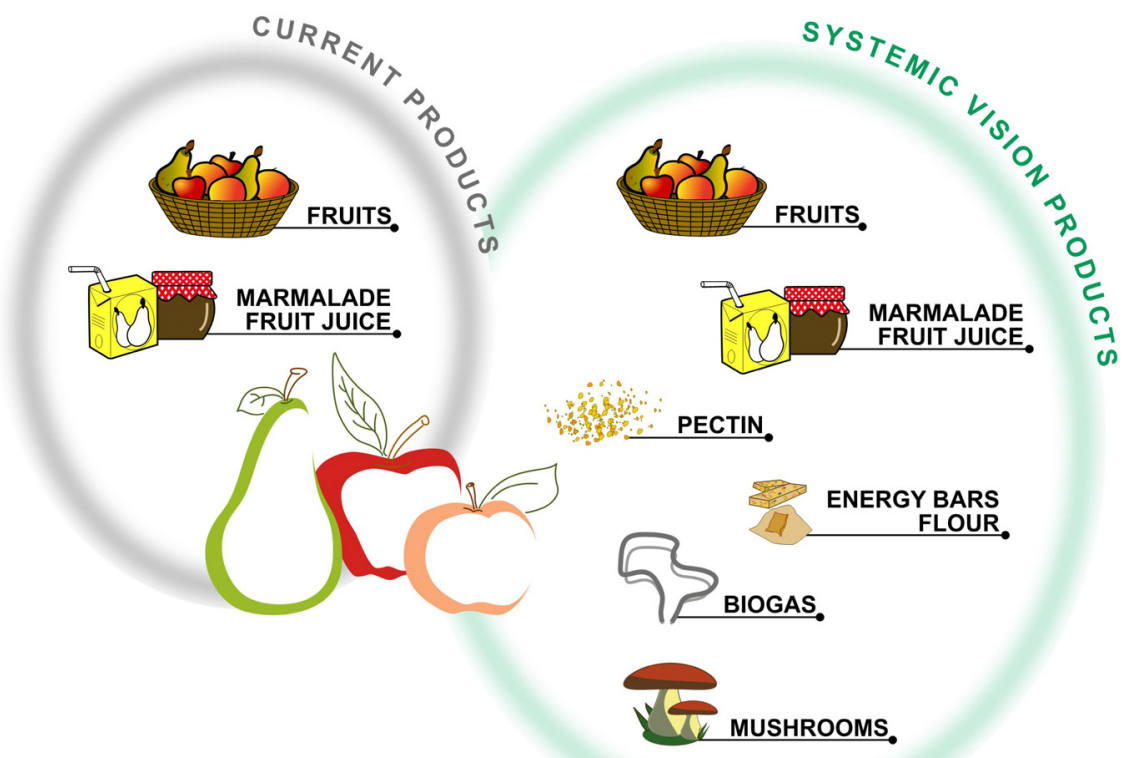

Figure 3: Differences between products from current fruit farming and products from the system proposed.

There is also an interesting proposal for a systemic cultivation that no longer uses synthetic pesticides but natural and equally effective methods that use the beneficial actions of insects, birds, grasses, mushrooms and bacteria for preventing and fighting against potential plant diseases. These methods can prevent fruit tree diseases caused by other plants or animals. This approach allows the fruit trees to be planted next to host trees and/or flowers that attract the insects, which would otherwise damage the fruit. High-quality products are thereby obtained that are completely natural and free of chemical traces that harm humans and animals. 


\section{Conclusion}

In conclusion, by adopting the principles of Systems Design to the current productive situations, it becomes possible to design open autopoietic selfsustaining production systems where wastes are enhanced with new value and become resources.

New flows of material are bringing together different industries that join forces to achieve the goal of zero emissions; material circulates continuously and diversity ensures the capacity to salvage.

This generates greater profits and benefits to the territory due to the development and improvement of the already established enterprises, the creation of new production scenarios and new products based on local know-how and the generation of new jobs.

It is a new business model: it allowed the production process to obtain higher economic profits, higher quality products enhanced with vital ethical and social values because they take into account human health, animal health and respect for the environment.

\section{References}

[1] Capra, F., The web of life, Anchor Books: New York, pp. 48-54, 1997.

[2] ZERI-Zero Emission Research and Initiatives, www.zeri.org

[3] Systems design-an autopoietic approach, www.systemsdesign.polito.it

[4] Turin chamber of commerce, www.to.camcom.it

[5] Ecocerved, www.ecocerved.it

[6] Legislative decree 3 April 2006 n. 152 - enclosure C - Italy.

[7] Legislative decree 3 April 2006 n. 152 - enclosure B - Italy.

[8] Turner, J., Factory farming and the environment,

[9] www. unsystem.org/SCN/archives/scnnews21/ch04.htm

[10] Gunter, P., Breakthroughs-What business can offer society, Epsilon Press: Surrey, UK, pp. 146-155, 1996.

[11] Legislative decree 15/2/2006 art. 184 paragraph 3 - Italy.

[12] Petrini, C., Buono, pulito e giusto, Gli struzzi Einaudi: Turin, pp. 20-25, 2005. 